\title{
ACHIEVING COST EFFECTIVE SUPPORT SOLUTIONS FOR THE NEW MILLENIUM THROUGH THE DoD AUTOMATIC TEST SYSTEMS SELECTION PROCESS
}

\author{
Jim Deffler \\ CASS Implementation Team Leader \\ Naval Air Warfare Center Aircraft Division \\ Lakehurst, NJ \\ (732)323-1202 \\ Email: Defflerjp@navair.navy.mil
}

\author{
Polly Gavord \\ ATS PGM Operations Office \\ San Antonio Air Logistics Center \\ Kelly AFB, TX \\ (210)925-9008 \\ Email: Pgavord@ldgate1.kelly.af.mil
}

\begin{abstract}
DoD policy is to minimize unique types of Automatic Test Systems (ATS) being introduced into the DoD inventory by using designated DoD families and by encouraging the use of commercial testers that meet defined hardware and software interfaces. This policy has been incorporated into DoD 5000.2-R of 15 March 1996 (with Change 3 of 23 March 1998), which is intended to define an acquisition environment that makes DoD the smartest, most responsive buyer of the best goods or services that meet our warfighters' needs at the best dollar value to the DoD over the life of the product. DoD 5000.2-R policy is implemented in the area of ATS by: (1) leveraging non-recurring investments already made in ATS Families across multiple applications, (2) evolving the capabilities of these Families of ATS by migrating their commercial item content towards industry-wide standards, (3) facilitating intra- and inter-service level interoperability by encouraging common and interoperable support solutions, and (4) encouraging the use of commercial items within ATS Families and as ATS alternatives. To implement this policy, the DOD ATS Executive Agent was chartered to establish and maintain a waiver process for those programs that propose not to use the $D O D$ designated standard families of ATS or commercial testers.
\end{abstract}

Contrary to popular belief, the DOD ATS Selection Process has been established to facilitate the mission of the DoD Program Manager by helping him or her choose the most cost effective ATS solution that fulfills his or her mission support requirements. The DOD ATS Family was not established to impose support solutions upon the DoD Program Manager, but rather to provide a variety of available and proven alternatives that may meet their needs while significantly reducing expected life cycle costs. Where obvious cost, schedule, or performance deficiencies exist with DoD family members for supporting a given weapon system, service ATS representatives can provide the knowledge and expertise to help identify suitable alternatives.

U.S. Government work not protected by U.S. copyright

\section{INTRODUCTION}

The DoD Automatic Test Systems (ATS) Executive Agent Office (EAO) was formed in 1994 to implement ATS acquisition policy as defined in DoD $5000.2-R$ of 15 March 1996 (with Change 3 of 23 March 1998). One of the EAO's charters was to develop and implement an ATS selection process to ensure that all current and future DoD ATS requirements are satisfied by the most cost beneficial solution to the DoD. Through a joint service effort, standard families of DoD approved testers were identified and the DOD ATS Selection Process was established. The Navy's Consolidated Automated Support System (CASS) and the Army's Integrated Family of Test Equipment (IFTE) were designated as the two initial DoD ATE families. DoD policy also encouraged the use of Commercial Offthe-Shelf (COTS) test equipment wherever appropriate. The DoD ATS Selection Process defined a Policy Deviation Request (PDR) for procuring or developing non-standard, noncommercial ATE and a Commercial Tester Acquisition Validation Request (CTAVR) for procuring COTS testers. All PDRs and CTAVRs submitted to the DOD ATS EAO are reviewed by a joint service team and are recommended for approval or disapproval by the ATS Management Board (AMB), which is made up of $0-6$ level representatives from all services.

Since its inception, the EAO has processed twenty-three PDRs and CTAVRs. The EAO, in consultation with the AMB principals, has made acquisition recommendations to appropriate Milestone Decision Authorities (MDAs) that have resulted in a total cost avoidance of $\$ 284$ million. The Marine's Third Echelon Test Set (TETS) and the Navy/Air Force Joint Service Electronic Combat Test 
System Tester (JSECST) were also added to the list of approved DoD Family Testers.

\section{OBJECTIVE}

While the DoD ATS Selection Process Team strives to ensure that ATS procurement decisions comply with DoD policy and represent the most cost beneficial ATS support solution to DoD over the life cycle, the team is constantly faced with adversity. Weapon System Program Managers (WSPMs) within the services feel that they are being told how to run their programs and spend their money while some members of industry feel they are being unfairly locked out of the DoD ATS market. Although the perception may be that the DoD ATS EAO is trying to force CASS and IFTE on WSPMs throughout $\mathrm{DoD}$, the fact is that the EAO only makes recommendations to the MDA. Final acquisition decisions are made by the appropriate MDA. Another chatlenge is that both DoD WSPMs and industry do not always understand all cost, programmatic, and mission issues that the DoD ATS Selection Process addresses.

There has been a strong thrust in recent years for DoD to use commercial equipment, standards, and practices wherever practical. Commercial technology now rivals and may often exceed military technology and DoD can realize a tremendous savings through the applicable use of commercial equipment and standards. There is also a great opportunity for DoD and industry to work together to solve common problems as exemplified by the Test \& Diagnostics Consortium (TDC). However, we must realize that commercial equipment, standards, and practices can not always be directly applied to the military environment. We must always remember that commercial industry and the military operate in two very different worlds. Delta does not offer flights to the USS Nimitz, Bradley tanks can not be repaired at the Sear's Automotive Department, and hopefully there are no Web sites selling HARM missiles over the internet.

To provide a better understanding of the issues that the DoD ATS Selection Process Team deals with, this paper attempts to apply common problems and issues to a hypothetical, commercial, non-military application.

\section{THE SCENARIO}

A manager (let's call him Don) of a UPS distribution and receiving center in a small city is about to request four new standard UPS delivery trucks to meet the demands of a recent boom in the city's industrial base - - obviously not the development and production of weapon systems. $\mathrm{He}$ has been sub-contracting out the excess workload, but this approach has proven to be far from cost effective and Don's performance ratings are based on his yearly Operations and Support (O\&S) costs. Of course, his annual O\&S account is charged \$100K (ATE production costs) for each new delivery truck that he requests.

Joe, his neighbor and a salesman at the local Ford dealership, is aware of Don's situation. Joe has also noticed that UPS makes deliveries each day to the dealership's service department. While about $60 \%$ of the packages are medium to large (WRAs or LRUs), the remaining $40 \%$ tend to be small packages and letters (SRAs or SRUs). Over a few drinks at lunch one afternoon, Joe suggests to Don that rather than requisition four new delivery trucks, he could buy four new Ford Explorers to handle the workload of the small packages and letters. Joe offers them to Don at $\$ 25 \mathrm{~K}$ each, fully loaded and including a cell phone to allow for communication with the central dispatcher. The cell phones are state-of-the-art and much easier and cheaper to operate than the antiquated radio dispatch systems that UPS uses (Easier TPS development and cheaper TPS production).

Joe sweetens the deal and offers an extended 5 year, 100,000 mile bumper-to-bumper warranty (corrective maintenance) and promises a $50 \%$ discount on all oil changes, tune-ups, etc (preventative maintenance and calibration). The $50 \%$ discount will also apply to any necessary repairs after the warranty expires. Besides, why should Don employ all those mechanics and technicians on the night shift when the dealership is just down the street?

Don thinks he's getting a heck of a deal - an immediate investment savings of $\$ 300 \mathrm{~K}$ with potentially tremendous sustainment savings over the life cycle. After lunch, Don follows Joe back to the dealership and orders the four Explorers.

\section{THE NEXT DAY}

Don gets into work early the next day, full of energy and excitement and eager to figure out all the money he will save. He gets right to work trying to project his savings over the next ten years. As Don begins to quantify his savings, he finally begins to think through the details. 
The cell phones far more reliable and cheaper to operate than those radio dispatch systems installed in UPS delivery trucks (TPS costs). Of course, the dispatcher can simultaneously communicate to the entire fleet of delivery trucks, alerting drivers of required pick-ups along their routes or traffic problems throughout the city. The dispatcher will have to call each of the Explorers separately and may have difficulty determining who is in the best location to make a pick-up (sounds like a TPS transportability problem).

Don also takes a hit on his yearly O\&S costs for each new employee that he sends to training. While delivery truck drivers require some training and a special license, anyone can drive a ford Explorer and that should save a few bucks. Don, being a former driver, remembers about corporate policy, customer relations, map reading and a variety of other issues and skills addressed in the standard UPS delivery person training program. Of course the bulk of the course was truck driving, so Don should be able to set-up a simple in-house program to address these other issues with new recruits (initial training costs).

The investment costs are starting to add up just a little but Joe did give Don a really good deal on those Explorers. After all they are obviously in high demand today as it will take six weeks before Joe can get Don the Explorers. Don could have had the four UPS trucks in two weeks and will have to continue sub-contracting out his excess workload for another month (interim support costs).

Although each Explorer comes with a spare tire and jack, Don realizes that he better by a few jumper cables, a few cans of fix-a-flat, some emergency flares and a few other odds and ends (initial calibration and support equipment investments) to minimize potential down-time. This brings up another concern. The Ford service department is only open Monday to Friday, 9 to 5 . Don can't afford any down time then. At $\$ 25 \mathrm{~K}$, he can buy another Explorer (provisioning spares) and he should still be ahead of the game. Don's investment cost savings aren't as great as he had originally thought, but he is sure to save on sustainment.

\section{THE BIG PAYOFF}

Don turns his attention to the big picture - there has got to be some big time savings over the next 10 years. Instead of hiring four more delivery truck drivers at a starting rate of $\$ 16.00$ an hour plus benefits, he should be able to find some reliable help for half that cost to drive the Explorers. Now that's a real manpower savings! Don's fleet is now 30 trucks, plus the four used by his sub-contractor. They all carry and pick-up large, medium, and small packages as well as letters and each truck has it's own route. Don designed the 34 routes himself to provide optimum coverage of the city and its surrounding suburbs. With the four sub-contractor trucks being replaced by the four Explorers which will only transport small packages and letters, he'll have to re-adjust those routes. This may result in longer routes and more overtime. He may also need one or two more sorters to separate the letters and small packages from medium and large ones (an added administrative burden). He'll be lucky to break even on manpower. The Explorer drivers are also more likely to want to move up in the company or move on, and he may have a higher turnover rate and may have to continually train new recruits. Even if the turn-over rate doesn't vary that much, he'll still have to maintain his in-house course on corporate policy and customer relations. He also has to maintain a larger staff of sorters, where he typically has a high turn-over rate. Don's sustaining training costs are sure to increase.

Another thought comes to Don's mind. He typically sees a significant increase in medium to large packages pass through his receiving and distribution center towards the end of November and all through December. Everyone pulls together and works their share of overtime (kind of like going into battle). Of course the Explorers won't be of much help with all those extra large packages. (Standard ATE solutions provide flexibility to meet surge support requirements!)

Don knows his maintenance costs are a big chunk of his operating budget at the receiving and distribution center. He employs a staff of three highly skilled mechanics on the graveyard shift. He's got that great extended warranty on those Explorers and he'll order a spare to avoid critical downtime. He only got a 3 year, 36,000 mile warranty on the last new car he bought. Of course Don only puts about 150 miles a week on his car and he anticipates that each of the new Explorer's will easily travel that distance each day. That great warranty won't last too long. (harsher operating environments). At least he's got that $50 \%$ discount on all repairs from Joe unless Joe should happen to take another job or hit the lottery and retire early. Don's maintenance costs would double unless he could find an alternate cost effective source of repair. (There are no guarantees that you won't be faced with parts obsolescence!) 
Maybe it won't be as inexpensive to maintain those Explorers after all.

As for his staff of highly skilled and highly paid mechanics, Don was not planning to add to it anyway. They do a terrific job maintaining his existing fleet of 30 delivery trucks and another four trucks really wouldn't affect their workload all that much. (In Service Engineering is sunk for standard ATE families). But now Don will need someone on the day shift to keep maintenance records on the Ford Explorers and to take them over to the dealer's service department for routine and corrective maintenance. What if there should be a recall on this year's model? Someone would have to take the Explorers to the service department to be updated. (Although the supplier may keep his product current and even offer free upgrades, there is still a program cost associated with this service.)

Well it's not even lunch-time and Don is about ready to call it a day and is quite frustrated. On the bright side, however, there are still some savings on his investment costs. Although business is good, budgets are still tight. If he saves a few bucks today, he'll look good and may move on by tomorrow.

\section{THE DAY OF RECKONING}

Six weeks go by and Don takes delivery of his four new Explorers, all brown, of course. He terminated the contract with his sub and those four delivery trucks are gone. The Explorers are loaded up with many letters and small packages and his new delivery persons are on their way. Things seem to be going pretty smooth. The last of Don's 30 delivery trucks is also soon loaded and on its way. To his surprise, Don finds a stack of large packages still on the loading dock - What went wrong? While $40 \%$ of the shipments were in fact small packages and letters, they only represent $10 \%$ of the truck space. (Smaller testers with less capability may be more than adequate to support SRAs/SRUs and simple WRAs/LRUs, but if these UUTs drive only a small ATE workload, that tester may not buy you anything.)

\section{THE MORAL OF OUR STORY}

Despite how something may first appear on the surface, things are not always what they seem. With mounting pressures to cut costs and improve productivity, one may be inclined to jump at what looks to be a sure thing. While some parts of this story may seem exaggerated, it serves to illustrate some very real misconceptions held by government weapon system managers and industry representatives alike.

The DoD ATS Selection Process Team understands these issues and with joint service representation sees them from the perspective of all services. The team was not established to enforce policy but to facilitate processes and help ensure that DoD gets the best value over its life cycle when buying ATS support. We are here to help! 